\title{
ADAPTIVE E-LEARNING SYSTEM BASED ON STUDENT ACTIVITY SKILLS IN MOOLDE SYSTEM
}

\author{
Aleksejs Jurenoks \\ Riga Technical University, Riga, Latvia
}

\begin{abstract}
Nowadays there are many views related to the online testing systems. The importance of acquisition of the final result is considered to be the main disadvantage in the classic test system where the learner chooses the correct answer from the suggested set of answers; this does not motivate a person to define the answer themselves or to create a logical chain of problem solutions. The integration of the intellectual processes into the existing training systems will prevent the drawbacks of the existing knowledge assessment systems and will make it possible to assess the learners' ability to make logical decisions, to clarify the answers using examples and to evaluate the method of achieving the result. The article describes the algorithm for creating the intellectual, user adapted questions; this algorithm uses the model of the learner from the set of questions and by fulfilling the modified Dijkstra's algorithm chooses the questions that help the learner reach the result that is most appropriate to their competence level.
\end{abstract}

Keywords: Adaptive system, Intelligent system, Moodle, Student classification, Quiz systems.

\section{Introduction}

Nowadays one of the ways how to check the learners' knowledge in the Latvian educational system is a test. Test in a broader sense is a standardized assessment of knowledge and comprehension using different types of tasks. In a narrower sense, it is an assessment of knowledge and comprehension through tasks with multiple choice questions. Tests can be used for the initial assessment, the formative assessment as well as the summative assessment. However, tests may be used during the learning process and for self-assessment in an equally successful way.

The tests used for evaluation are based around everything that has been learnt during the learning process. In order to create the task system, it is recommended to progress from simpler to more complex tasks, thus checking the students' knowledge and understanding of using the appropriate knowledge in a standardized situation as well as in a new situation that has not been dealt with prior.

Tests are often used for formative assessment purposes and the number of questions that they contain should not exceed 7 to 10 questions. By contrast, 
summative assessment involves a complex test consisting of test questions and tasks which examine the use of knowledge and creative skills. The summative assessment can also take a combination such as this: test + research.

Nowadays there are many views related to the testing systems. The importance of acquisition of the final result is considered to be the main disadvantage in the classic test system where the learner chooses the correct answer from the suggested set of answers (Niemiec et al., 2009); this does not motivate a person to define the answer themselves or to create a logical chain of problem solutions. This is the reason why testing does not always allow determining the actual level of the learner's knowledge. Other authors have proven (El Bachari et al., 2010) that when carrying out the assessment of the learner's knowledge by using open questions and tests, the results obtained by using tests are $48 \%$ better than using the open question form.

The integration of the intellectual processes into the existing training systems (utilisation of the artificial intelligence methods) will prevent the drawbacks of the existing knowledge assessment systems and will make it possible to assess the learners' ability to make logical decisions, to clarify the answers using examples and to evaluate the method of achieving the final result.

The article describes the algorithm for creating the intellectual, user adapted questions; this algorithm uses the model of the learner from the set of questions and by fulfilling the modified Dijkstra's algorithm chooses the questions that help the learner reach the result that is most appropriate to their competence level.

\section{Related works}

Thanks to the rapid development of the modern technology, nowadays a new generation of learners has emerged - they use only electronic resources in order to acquire new knowledge (Abraham et al., 2013). Despite the fact that today's systems can provide full educational process by using the method of presenting information mentioned prior, the way of presenting information is not always acceptable to all groups of learners. Nowadays the online educational systems can be divided into three relative groups (Azough et al., 2010): Learning managements system, Synchronous collaboration, and all other computer tools including asynchronous collaboration. Whilst working with training systems, the user must choose the category of the training system for themselves and they must also adapt to the training course methodology. The research nowadays has shown that when using a static training system, the user cannot choose the training style that fits their personal needs which has resulted in: $39 \%$ of the time it being a reason to stop learning or $40 \%$ of the time it being a reason to simply skip incomprehensible or difficult topics and master them through other systems or courses (Abraham et al., 2013). 
In their work (El Bachari et al., 2010) it has been proven that using adaptive learning systems lets a person choose the learning content and the way of presenting information; it also increases the quality of the course by $28 \%$ by reducing the rate of terminating a course by $60 \%$.

The tools of today only partially solve traditional problems which are related to the intelligent training systems. It is scientifically proven (Surjono, 2011) that the main obstacle in implementing the intelligent training systems is related to the integration of the decision-making algorithm in the environment of a training system and its connection with the user model. Nowadays the intelligent training systems mainly have the adaptive rather than the intelligent functions.

\section{The development of the learning model by using the Moodle learning system}

In order to provide the customization of information for every student, an intellectual agent has been integrated into the Moodle system and by taking four steps it makes it possible to define the necessary requirements for the selection of information from the common Moodle data sets which corresponds to the specific learner's ability and needs:

- Data selection. The training system identifies each user through a unique identification code and collects the information on the system usage intensity and the number of resources used. By taking this step, the user's model has been defined indicating the topics which the learner has mastered as well as the topics which they have viewed on a regular basis following the current task.

- Pre-processing the information. The received information is automatically summarized and structured in the format of a new table. MySQL System Tray Monitor and Administrator tools are used for data pre-processing by using the expert-defined requirements.

- Apply association rule mining. The data mining algorithms (Delgado et al., 2010) are applied to discover and summarize knowledge of interest to the teacher.

- Defining the user model coefficient. One of the factors that determines the learner's achieved results are the results of the electronic training system self-assessment tasks. The received results define the learning process of the category and the further direction in order to achieve the final results. The teacher will use the received data for making decision about the students and the Moodle activities of the course in order to improve the students' learning skills. 
Within an working system it is impossible to obtain all the necessary information to define the user model. Some base values of the model, such as the time which is spent using the Moodle system or the amount of resources viewed, do not always indicate the actual time spent in the system, but only the time while a remote session is open and the system remains active. As a result, there are some restrictions that do not allow preparing all the necessary information in order to adapt the course material:

- It is not possible to find out how a user will behave and what kind of material they will look at. Also the learner's demand might be unchanged or the system user will use the expected information selection process or any casual requests.

- The results which are acquired whilst completing the tasks of selfassessment cannot be categorized or do not allow defining the priority themes.

As a result, it can be concluded that in order to monitor the result of the learner's knowledge acquisition, a physical audit is necessary and it can be conducted by using self-assessment questions. There are often situations when previously prepared tests do not provide the actual results and they do not motivate the learners to revise the material acquired prior. Thus, when receiving the minimum permitted mark in a test, the learner moves on to the next topic where the previously skipped topics are no longer discussed. Nowadays, this issue can be resolved only by involving a real expert who will manually adjust the learning materials of each topic for learning model of the learner.

\section{The use of question metrics in the process of designing a test}

This article has proposed a method for designing self-assessment tasks where the selection of questions is implemented by using the graph theory. Suppose that a set of questions which can be used to achieve the result $D$ has been assigned a matter of metrics $l(S(s)$ ), a value which is located in the indexed set and can be used in comparison. In the models suggested by other author (Гекк et al., 2006), the metrics are built using recursive approach from top to bottom, defining the conditions for establishing the route.

For the question selection algorithm to be effective it is necessary to meet three conditions: determining the importance of the question, preservation of priorities, and the determination of the importance of a question.

Determining the importance of the question. The selectable question $v$ is useful for the test $u$, if the condition is fulfilled (formula 1): 


$$
\left(\begin{array}{c}
S\left(v_{1}\right) \\
S\left(v_{2}\right) \\
\cdots \\
S\left(v_{n}\right)
\end{array}\right)_{T} \underset{t, \text { select }}{\longrightarrow}\left(\begin{array}{c}
S\left(v_{i_{1}}\right) \\
S\left(v_{i_{2}}\right) \\
\ldots \\
S\left(v_{i_{n}}\right)
\end{array}\right)_{T}
$$

where $S\left(v_{i_{j}}\right)>S\left(v_{i_{j+1}}\right), \mathrm{j}=1,2, \ldots, \mathrm{n}-1$.

Its condition plays an important role. All metrics, whose rates are low, will be selected from the metrics list $S(u)$ (the questions were not covered before or the learner has made several errors while filling in questions of a similar category). Accordingly, there will be no possibility to choose the test questions which the student can easily answer or has already answered successfully before.

Preserving the priorities. The metric preserves its priority if the $l(S(v)) \leq$ $l(S(u v))$ follows with $l(S(u) \leq l(S(v) \oplus S(u))$ for all $\forall v \in V$ and $\forall u \in N(v)$. This means that before adding a new question u to the list $S(v)$, it is evaluated as to whether it will be better than anyone else from the list $S(v)$.

Defining the importance of a question. It determines the behaviour of the metrics through the full test question reconfiguration. Let us assume that $R(v)=$ $\left(v_{1}, v_{2}, \ldots, v_{n}\right)$ is the set of questions for the $u$ test. Let us introduce an additional list $R^{*}(v)$ with questions that are sorted in the ascending order of the metrics $l\left(S\left(v_{n}\right)\right) \leq l\left(S\left(v_{n+1}\right)\right)$. The arranged list of metrics will allow choosing the number of the most important questions for the $v$ test (formula 2):

$$
l\left[S_{R *(v)}(v)\right] \leq\left[S_{R *(v)(v)}\right] .
$$

\section{The algorithm of the intellectual question selection}

The Dijkstra's procedure is considered to be the basis of the classic information search algorithm in the graph (Вабищевич et al., 2010). When implementing the procedure each question in the database is accompanied by two variables - prior(v) indicating the frequency of using the question $v$ and $\operatorname{pred}(\mathrm{v})$ which indicates the location of the question $v$ in the test. The starting value of the variable $\operatorname{prior}(v) \rightarrow \infty$ has been defined. This means that the question has not been viewed yet. The starting value of the variable $\operatorname{pred}(v)=0$-this means that the questions do not have a determined location in the test or that the location does not matter.

It is defined that the usage ratio of a question is a positive number. In this case, it is proposed to use the Dijkstra's algorithm (figure 1.) provided that - 
$l(u, v) \geq 0$. As a result, the path of the graph must be built through questions with a minimum utilization coefficient.

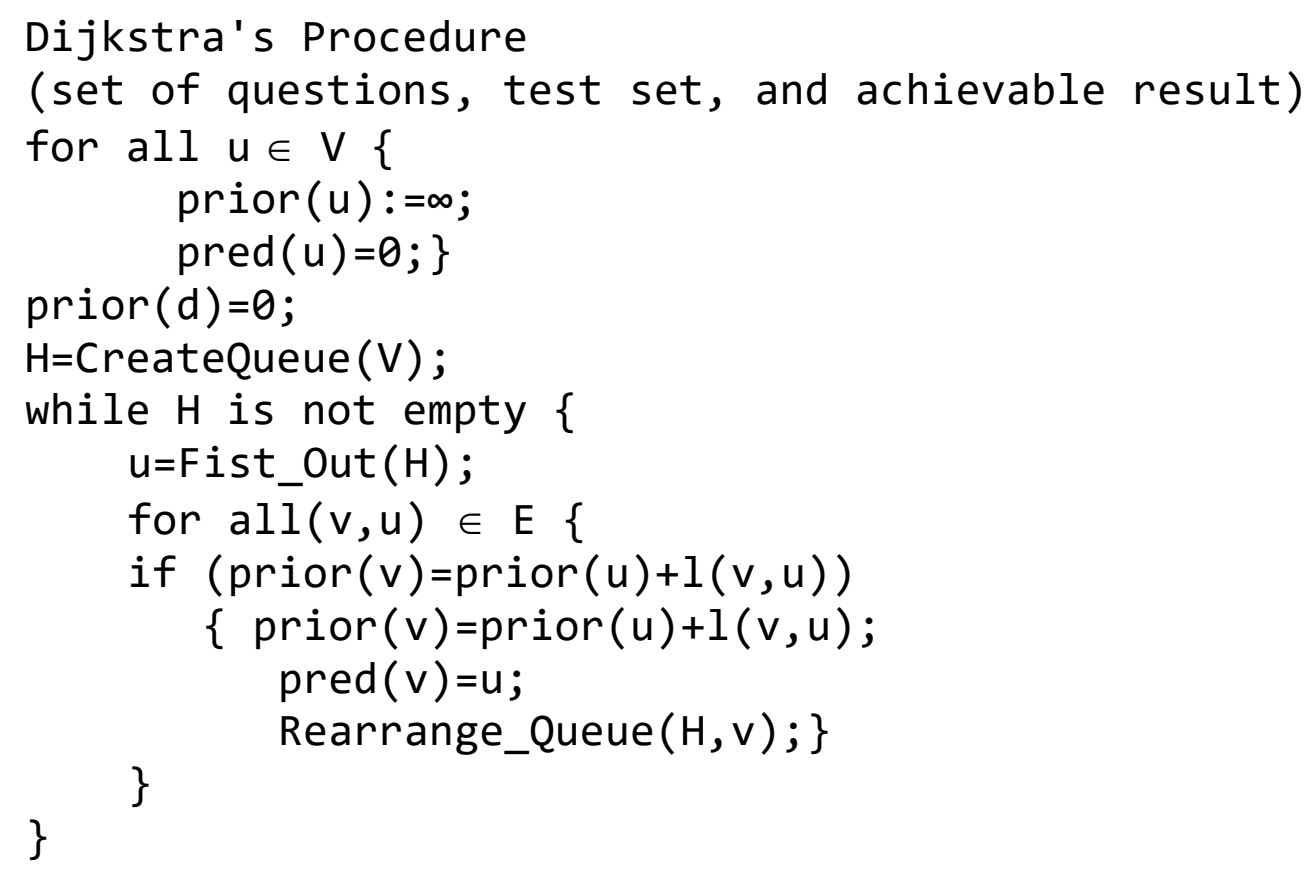

A significant difference in the procedures is the use of line $H$ where all the elements are sorted using prior(v) values. The procedure CreateQueue() creates the line of question priorities $H$ by replacing the question of the start of the line with the lowest usage coefficient prior $(v)=0$. The procedure Rearrange_Queue $(H, v)$ provides the reconfiguration of the line in case of priorities or usage of the questions.

Every time when performing a while cycle two conditions are met:

1. There is a $d>0$ value where all the questions viewed $-\operatorname{prior}(v) \leq d$ and all the remaining questions of the line $-\operatorname{prior}(v) \geq d$.

2. The value $\operatorname{prior}(v)$ for each question $\mathrm{v}$ in the line is equal to $\infty$ or the minimum coefficient which points to the need of including the question; moreover, the frequently used in questions or the questions which do not meet the aim are removed from the line.

The completion of the requirements guarantees the result of the algorithm solution (figure 1).

If it is necessary to evaluate the change in metrics through a dynamic question selection the use of Bellman-Ford algorithm (Golderg et al., 1993) is suggested. When the algorithm is in action, the starting value of the metrics of each question may vary multiple times depending on the results received during the tests. Every time the change in metrics is conducted by using the procedure (3):

$$
\operatorname{Update}{ }_{-}(v, u): \operatorname{prior}(v)-\min \left\{\operatorname{prior}(v), \operatorname{prior}(u)_{-} l(v, u)\right\}
$$



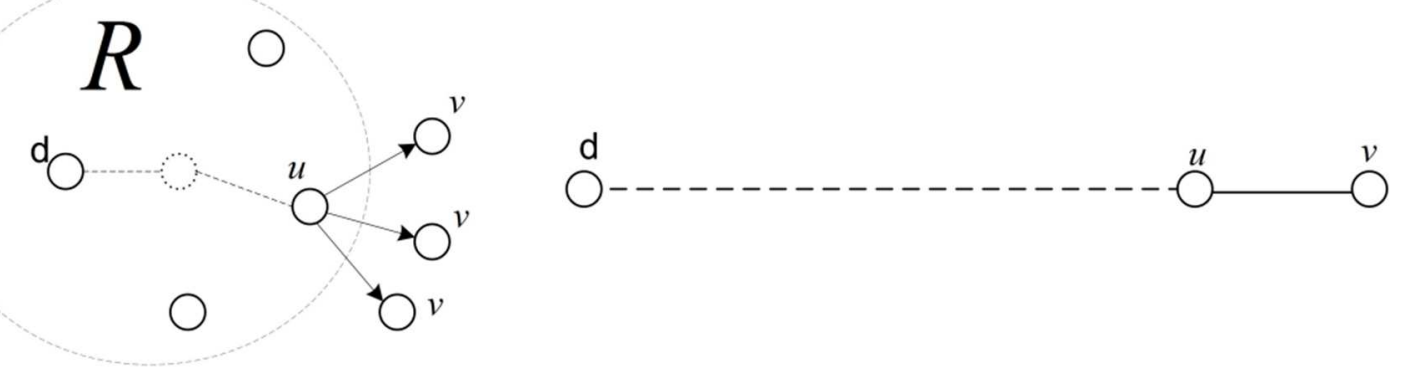

Fig.1 Application of Dijkstra's algorithm

During the procedure certain characteristics are conducted:

- the use of the procedure does not increase prior(v) values;

- the most effective result corresponds to a minimal prior(v) value, therefore the regular $U p d a t e \_M$ procedure will not affect the results negatively.

The proposed algorithm creates a test looking at all the questions from the group $S(v)$ if the question usage coefficient is available to the $l(S(v))$ metrics. Where it is not possible to identify the value of the question usage, the algorithm for creating intellectual questions is no longer able to work.

\section{Conclusions}

Nowadays, an intelligent E-Learning system allows teachers to monitor students' learning process. Online analytics tools prove to be highly practical when working with students' process validation, what mistakes they can have, and how they are interacting with course content. Teachers can change or adapt their lessons structure and main content. Moodle framework is highly reliable and encourages students with semantic and other motivated courses by using adaptive e-learning. But it lacks the feature of social interaction especially when it comes to interact with teachers and the meaning of sharing experience.

The article describes the algorithm for creating the intellectual, user adapted questions; this algorithm uses the model of the learner from the set of questions and by fulfilling the modified Dijkstra's algorithm chooses the questions that help the learner reach the result that is most appropriate to their competence level.

In result, general architecture of intelligent questioner module for e-learning intelligent system was described in this paper. The objective is to make a system work like a real teacher which can model the description of pedagogic resources and guide the learner in his educational process according to his assets and to the pedagogic objective that is defined by the teacher. 


\section{References}

Abraham, G., Balasubramanian, V., \& Saravanaguru, R. A. K. (2013). Adaptive e-Learnins Environment using Learning Style Recognition. International Journal of Evaluation and Research in Education, Vol.2, 23-31.

Azough, S., Bellafkih, M., \& Bouyakhf, El. H. (2010). Adaptive E-learning using Genetic Algorithms: IJCSNS International Journal of Computer Science and Network Security”, Vol.10 No.7, July 2010.

Delgado, M., Gibaja, E., Pegalajar, M. C., \& Pérez, O. (2006). Predicting Students' Marks from Moodle Logs using Neural Network Models. Current Developments in Technology Assisted Education, Badajoz, 586-590.

El Bachari, E., Abelwahed, E., \& El Adnani, M. (2010). An Adaptive Learning Model Using Learner's Preference. International Conference on models of information and communication systems, ENSIAS, Rabat, Morocco.

Goldberg, A. V. \& Radzik, T. (1993). A Heuristic Improvement of the Bellman-Ford Algorithm. Applied Mathematics Letter, 6 (3), 3-6.

Niemiec, C., \& Ryan, R. M. (2009). Autonomy, competence, and relatedness in the classroom. Applying self-determination theory to educational practice. Theory and Research in Education, Vol. 7 (2), 133-144.

Surjono, H. D. (2011). The design of adaptive e-Learning system based on student's learning styles. International Journal of Computer Science and Information Technology (IJCSIT), vol. 2, no. 5, 2350-2353.

Вабищевич, А. Н. (2010). Определение положения в пространстве элементов беспроводной сенсорной сети с помощью инерциальных сенсоров. Tезисbl докладов научно-технической конференции студентов, аспирантов и молодых специалистов МИЭМ 2010. М.: МИЭМ, 151-152.

Гекк, М. В., Истомин, Т. Е., Файзулхаков, Я. Р., \& Чечендаев, А. В. (2006). Адаптивный алгоритм быстрой доставки сообщений по выделенным направлениям. Вестник молодых ученых "Ломоносов". Выпуск III, 55-60. 